\title{
Kualitas Hidup Pasien Pascaintervensi Koroner Perkutan
}

\author{
Remita Ully Hutagalung ${ }^{1}$, F. Sri Susilaningsih ${ }^{2}$, Ai Mardiyah ${ }^{2}$ \\ ${ }^{1}$ Fakultas Keperawatan Dirgahayu Samarinda, ${ }^{2}$ Fakultas Keperawatan Universitas Padjadjaran \\ E-mail: itanauli@yahoo.ca
}

\begin{abstract}
Abstrak
Penyakit jantung koroner adalah penyakit yang dapat mengancam kehidupan seseorang. Pelaksanaan tindakan non bedah intervensi koroner perkutan pasien masih memiliki risiko terjadinya serangan berulang, stenosis dan ancaman kematian. Tujuan penelitian ini adalah mengidentifikasi kualitas hidup pasien pascatindakan intervensi koroner perkutan. Desain penelitian ini adalah potong lintang. Pengambilan sampel secara consecutive sampling didapatkan 50 responden yaitu pasien yang sedang kontrol pascaintervensi coroner per kutan di Poliklinik Spesialis Jantung RSUP Dr. Hasan Sadikin Bandung, penelitian ini dilakukan pada 1-14 November 2013. Kualitas hidup diukur dengan instrumen $W H O Q O L-B R E F$ dengan empat domain kualitas hidup yaitu domain fisik, psikologis, sosial, dan lingkungan. Analisis menggunakan statistik deskripsi. Hasil penelitian menunjukkan bahwa responden memiliki kualitas hidup baik sebesar 50\%. Perawat memiliki peran dalam membantu pasien mencapai kualitas hidup yang optimal, diantaranya melalui peningkatan efikasi diri pasien melalui pendampingan dan pemberian informasi dalam usaha mencapai kualitas hidup.
\end{abstract}

Kata kunci: Intervensi koroner perkutan, kualitas hidup, WHOQOL-BREF.

\section{The Quality of Life of Patient with Post Percutaneous Coronary Intervention}

\begin{abstract}
Coronary heart disease is a disease that can threaten person's life, and can lead to the change of the quality of life. This coronary heart disease can be solved with non-surgical called percutaneous coronary intervention. This action will be normalized the quality of perfusion in the coronary arteries, which would certainly have an impact on the quality of life of patients. The research objective was to observe the patient of quality of life after treatment on intervention percutaneous coronary. The research design was cross sectional. There were 50 respondents taken by consecutive sampling. Data were collected in outpatient room in RSUP Dr. Hasan Sadikin Bandung, who have came with treatment routine schedule after percutaneous coronary intervention during November 1st-14th 2013. The questionnaire use WHOQOL-BREF format with 26 questions that consisting of 4 domains of quality of life: physical domain, psychological domain, social domain, and environment domain. Majority of patients were male $(74 \%)$, with the range of age mostly 56-66 years ( $34 \%$ ), married ( $96 \%$ ), college education was the highest ( 66 $\%$ ), the majority had not a primary job like as housewife, retired, student, etc. ( $26 \%$ ). Data were collected using the questionnaire WHOQOL - BREF. The result have shown that rates of quality of life was good ( $50 \%)$ and health condition after percutaneous coronary intervention neither satisfied nor dissatisfied ( $44 \%)$. Nurses have a role in helping patients achieve optimal quality of life like giving information to patient correctly
\end{abstract}

Key words: Percutaneous coronary intervention, quality of life, WHOQOL - BREF. 
Remita Ully Hutagalung: Kualitas Hidup Pasien Pascaintervensi Koroner Perkutan

\section{Pendahuluan}

Profil Kesehatan Indonesia pada tahun 2008 menunjukan adanya pergeseran pola penyakit di Indonesia dalam 12 tahun terakhir (19952007). Proporsi penyakit menular menurun dari $44 \%$ menjadi $28 \%$, sedangkan proporsi penyakit tidak menular yang termasuk di dalamnya adalah penyakit jantung koroner (PJK) mengalami peningkatan dari $42 \%$ menjadi $60 \%$. Data penyakit penyebab kematian menurut golongan sebab akibat di rumah sakit di Indonesia pada tahun 2007 adalah penyakit pada sistem sirkulasi darah termasuk penyakit jantung koroner yang berada di urutan pertama. Gambaran profil kesehatan Indonesia ini mendukung pernyataan yang telah dikeluarkan WHO (Depkes RI, 2009).

Penyakit jantung koroner adalah penyakit jantung yang disebabkan oleh adanya penyempitan pembuluh darah arteri koroner akibat proses aterosklerosis atau spasme atau keduanya. Penyakit jantung koroner menyebabkan masalah pada organ jantung dan terutama di bagian pembuluh darah. Sindrom koroner akut (SKA) merupakan penyakit jantung koroner serius yang mengancam kehidupan karena dapat menyebabkan kematian secara mendadak (Depkes RI, 2009).

Penyakit jantung koroner pada tahun 2008 telah menyebabkan kematian sebanyak 17,3 juta orang (30\%). Diperkirakan pada tahun 2030, sebanyak 23,3 juta penduduk dunia akan meninggal akibat berbagai penyakit kardiovaskular (WHO, 2013). Jumlah hasil penelitian ini akan terus meningkat di daerah Asia, termasuk Indonesia (Sasayama, 2013 ).

Masalah utama dari PJK adalah terjadinya penyempitan di pembuluh darah yang terjadi akibat proses aterosklerosis atau spasme arteri atau keduanya. Aterosklerostik terjadi akibat adanya timbunan kolesterol dan jaringan ikat pada dinding pembuluh darah secara perlahan-lahan (Price \& Wilson, 2010). Kondisi tersebut menyebabkan miokard atau otot jantung tidak mendapatkan suplai oksigen dan darah, maka perburukan mengarah dari iskemia sampai dengan kematian jaringan di jantung (Corwin, 2008). Penyakit jantung koroner tersebut dikategorikan sebagai penyakit kritis karena pasien berada dalam kondisi adanya ancaman kematian.

Penanganan nonbedah untuk mengatasi PJK adalah dengan pemberian terapi fibrinolitik dan tindakan intervensi koroner perkutan (IKP). Penelitian yang lainnya menyebutkan bahwa penanganan dengan terapi fibrinolitik merupakan cara tercepat untuk mengatasi aterosklerotik pada pasien penyakit PJK sebelum dilakukan tindakan lebih lanjut, akan tetapi publikasi ilmiah yang lain menyatakan bahwa tindakan intervensi koroner perkutan adalah penanganan terbaik bagi pasien yang mengalami serangan jantung dengan ST elevasi yang sering dialami pasien jantung koroner. Perbandingan angka keberhasilan tindakan terapi fibrinolitik dan IKP berdasarkan hasil penelitian melalui Gusto II menyatakan bahwa risiko terjadinya kematian dan serangan jantung berulang setelah dilakukan intervensi koroner perkutan sebesar 9,6\%. Perbandingan antara fibrinolitik dan IKP menunjukan bahwa terapi fibrinolitik memeliki angka kematian dan serangan jantung berulang sebesar 13,7\%. Sehingga dapat disimpulkan bahwa intervensi koroner perkutan dapat menurunkan risiko kematian dan serangan berulang (Keeley \& Hillis, 2007).

Intervensi koroner perkutan adalah terminologi yang sering digunakan untuk menerangkan berbagai prosedur yang secara mekanik berfungsi untuk meningkatkan aliran ke miokard. PJK adalah kondisi penyakit dimana terganggunya perfusi ke miokard. Tindakan intervensi koroner perkutan telah menjadi solusi dibandingkan tindakan pembedahan seperti CABG (Coronary Artery Bypass Graft), karena intervensi koroner perkutan adalah intervensi tanpa melakukan tindakan pembedahan. Intervensi koroner perkutan juga dapat digunakan sebagai alat prosedur diagnostik inpassive dimana satu atau lebih kateter dimasukkan ke jantung dan pembuluh darah tertentu untuk mengukur tekanan dalam berbagai kamar jantung dan untuk menentukan saturasi oksigen dalam darah (Smeltzer \& Bare, 2002). Jenis IKP atau tindakan kateterisasi jantung koroner pada pasien jantung meliputi angiografi koroner dan IKP (Huynh, dkk., 2009).

Kehadiran IKP dinilai merupakan tindakan 
yang efektif untuk mengatasi masalah pada pembuluh darah koroner. Intervensi koroner perkutan adalah tindakan intervensi jantung yang paling sering digunakan sebagai intervensi untuk mengatasi masalah pembuluh darah (Zhao, 2008). Intervensi koroner perkutan merupakan suatu tindakan angioplasty (dengan atau tanpa pemberian stent) yang bertujuan untuk membuka pembuluh darah koroner yang bermasalah yang dapat menimbulkan infark, diikuti atau tanpa ST elevasi (Keeley \& Hillis, 2007).

Menurut Turkish society of Cardiology pada tahun 2007, bentuk-bentuk IKP terdiri dari percutaneous transluminal coronary angioplasty (PTCA), percutaneous coronary atherectomy percutaneous coronary laser angioplasty, placement of percutaneous coronary stent, dan brachytherapy. koroner perkutan bertujuan untuk meningkatkan harapan hidup dan kualitas hidup pasien, tetapi ternyata beberapa literatur dan hasil penelitian menunjukkan bahwa IKP masih meninggalkan beberapa masalah yang terkait dalam kualitas hidup pasien, diantaranya depresi dan cemas (Zhao, 2008; Rachmayanti, 2013), peningkatan mortalitas oleh karena adanya restenosis (Gunal, dkk., 2008; Moonen, Van't Veer, \& Pijls, 2010), mudah letih, irritable, ekshausi, disfungsi seksual (Blankenship, dkk., 2012), embolisasi, dan peningkatan penggunaan beta bloker. Belum ada hasil penelitian yang secara jelas menyatakan bahwa IKP dapat memberikan perbaikan terhadap kualitas hidup pasien secara optimal (Weintraub, dkk., 2008).

Konsep kualitas hidup yang didefinisikan oleh World Health Organization (WHO) melalui WHOQOL (World Health Organization Quality of Life) adalah sebagai persepsi individu tentang keberadaannya dalam hidup yang terkait dengan budaya dan sistem nilai di lingkungan dia berada dalam hubungannya dengan tujuan, harapan, standar, dan hal hal menarik lainnya (Lucas, 2012). Kualitas hidup dipengaruhi oleh persepsi individu mengenai keadaan mereka dalam kehidupan dalam konteks budaya dan sistem nilai dimana mereka hidup. Pemahaman ini berhubungan dengan tujuan hidup, harapan, dan standar yang menjadi keyakinan individu itu sendiri (Lucas, 2012). Kualitas hidup adalah pengalaman unik setiap individu yang terkait dengan nilai-nilai yang mereka pahami sebagai keyakinan. Kualitas hidup merupakan rasa kesejahteraan setiap orang terkait dengan kehidupannnya. Kualitas hidup pasien yang optimal menjadi isu penting yang harus diperhatikan dalam memberikan pelayanan keperawatan yang komprehensif (Ibrahim, 2009).

\section{Metode Penelitian}

Penelitian ini menggunakan metode deskriptif dan penentuan sampel diambil dengan teknik non probability sampling. Responden yang menjadi sampel adalah pasien pascaintervensi koroner perkutan yang datang ke poliklinik spesialis jantung RSUP Dr. Hasan Sadikin Bandung pada Bulan November 2013 berjumlah 50 orang. Karekteristik yang dikaji meliputi jenis kelamin, usia, pekerjaan, pendidikan, status pernikahan, dan lama waktu pasca-IKP. Kualitas hidup dikaji melalui kuesioner WHOQOL-BREF yang berisi 26 pertanyaan terdiri dari domain fisik, psikologis, sosial, dan lingkungan. Data dianalisis secara deskriptif dan disajikan dalam bentuk tabulasi (Skevington, Lotfy, \& O’Connell, 2004).

\section{Hasil Penelitian}

Rentang waktu pasca-IKP menunjukkan hasil yang bervariasi. Keseluruhan pasien berasal dari Provinsi Jawa Barat. Distribusi pasien berdasarkan jenis kelamin didapatkan pasien laki-laki lebih banyak (74\%) dibanding pasien perempuan $(26 \%)$. Usia paling banyak pada rentang 56-65 tahun (34\%). Status pernikahan mayoritas menikah (96\%). Pendidikan formal sampai dengan perguruan tinggi terbanyak $(66 \%)$. Penilaian kualitas hidup mayoritas pasien mengalami kualitas rendah di domain sosial $(70 \%)$ dan lingkungan $(70 \%)$. Pasien pasca-IKP menyatakan bahwa kualitas hidup mereka baik ( $25 \%$ ) dengan status kesehatan biasa saja ( $22 \%)$.

\section{Pembahasan}

Hasil penelitian ini menunjukkan jenis 
Remita Ully Hutagalung: Kualitas Hidup Pasien Pascaintervensi Koroner Perkutan

kelamin pasca-IKP yang datang kontrol pada tanggal 1-14 November 2013 lebih banyak laki-laki dari pada pasien perempuan.
Tindakan IKP adalah tindakan yang ditujukan untuk memperbaiki aliran pembuluh darah arteri koroner pada pasien dengan PJK

Tabel 1 Karekteristik Pasien Pasca-IKP di RSUP Dr. Hasan Sadikin Bandung

\begin{tabular}{|c|c|c|}
\hline Keterangan & Jumlah & $(\%)$ \\
\hline \multicolumn{3}{|l|}{ Jenis Kelamin } \\
\hline Laki laki & 37 & (74) \\
\hline Perempuan & 13 & (26) \\
\hline \multicolumn{3}{|l|}{ Usia } \\
\hline 17-25 tahun & 1 & (2) \\
\hline 26-35 tahun & 2 & (4) \\
\hline 36-45 tahun & 4 & $(8)$ \\
\hline 46-55 tahun & 15 & $(30)$ \\
\hline 56-65 tahun & 17 & (34) \\
\hline$\geq 66$ tahun & 11 & $(22)$ \\
\hline \multicolumn{3}{|l|}{ Status Menikah } \\
\hline Menikah & 48 & $(96)$ \\
\hline Tidak menikah & 2 & (4) \\
\hline \multicolumn{3}{|l|}{ Pendidikan } \\
\hline $\mathrm{SD}$ & 2 & (4) \\
\hline SLTP & 2 & (4) \\
\hline SLTA & 13 & (26) \\
\hline Perguruan tinggi & 33 & $(66)$ \\
\hline \multicolumn{3}{|l|}{ Pekerjaan } \\
\hline Bekerja & 24 & $(48)$ \\
\hline Tidak bekerja & 26 & $(52)$ \\
\hline \multicolumn{3}{|l|}{ Lama Waktu pasca-IKP } \\
\hline 1 tahun & 25 & $(50)$ \\
\hline$\geq 1$ tahun & 25 & $(50)$ \\
\hline \multicolumn{3}{|c|}{ Kualitas Hidup menurut Responden Pasca-IKP } \\
\hline Buruk & 4 & (8) \\
\hline Biasa biasa saja & 16 & (32) \\
\hline Baik & 25 & $(50)$ \\
\hline Sangat baik & 5 & $(10)$ \\
\hline \multicolumn{3}{|c|}{ Kepuasan terhadap Kesehatan Pasca-IKP } \\
\hline Tidak memuaskan & 9 & (18) \\
\hline Biasa biasa saja & 22 & (44) \\
\hline Memuaskan & 15 & $(30)$ \\
\hline Sangat Memuaskan & 4 & $(8)$ \\
\hline \multicolumn{3}{|l|}{ Kualitas hidup fisik } \\
\hline Rendah & 18 & $(36)$ \\
\hline Tinggi & 32 & $(64)$ \\
\hline
\end{tabular}


Remita Ully Hutagalung: Kualitas Hidup Pasien Pascaintervensi Koroner Perkutan

\begin{tabular}{lcc}
\hline \multicolumn{1}{c}{ Keterangan } & Jumlah & (\%) \\
\hline Kualitas Hidup Psikologis & & \\
Rendah & 24 & $(48)$ \\
Tinggi & 26 & $(52)$ \\
Kualitas Hidup Sosial & & \\
Rendah & 35 & $(70)$ \\
Tinggi & 15 & $(30)$ \\
Kualitas Hidup Lingkungan & & \\
Rendah & 35 & $(70)$ \\
Tinggi & 15 & $(30)$ \\
\hline
\end{tabular}

(Turkish Society of Cardiologi, 2007). Penelitian yang lainnya menyatakan laki-laki berpotensi besar untuk mengalami penyakit jantung (Huynh, dkk., 2009; NHLBI, 2012; World Heart Federation, 2014). Pernyataan tersebut didukung dengan teori bahwa wanita mempunyai risiko yang lebih rendah mengalami PJK sebelum masa menopause, karena adanya kerja hormon estrogen yang meningkatkan kerja HDL dan menekan kerja LDL (lemak jahat). Perubahan nilai HDL dan LDL merupakan lemak yang berkontribusi dalam terjadinya penyakit gangguan pada pembuluh darah (Guyton \& Hall, 2000). Pembuluh darah koroner akan mengalami gangguan elastisitas (terjadinya spasme karena aterosklerotik) jika mengalami kondisi seperti adanya aterosklerotis, diabetes melitus, hiperkolesterol, dan hipertensi. Kondisi tersebut menyebabkan penurunan aliran darah ke jantung dan akhirnya memperberat kondisi kerja jantung (Smeltzer \& Bare, 2002).

Rentang usia 56-66 tahun adalah jumlah terbesar pasien pasca-IKP dalam penelitian ini. Rentang usia ini adalah rentang usia yang dikategorikan lanjut usia. Lanjut usia merupakan usia yang memiliki risiko mengalami masalah pada pembuluh darah. Sejalan dengan penelitian yang dilakukan oleh Chan, Chau dan Chang (2005) bahwa rata rata usia mengalami jantung koroner adalah pada usia 33-87 tahun. Sejalan dengan penelitian Baas (2004) rentang usia yang mengalami masalah di pembuluh darah koroner adalah 36-81 tahun. Hasil penelitian yang berbeda terdapat pada penelitian.
Steigelman (2006) yang menyatakan rentang usia risiko mengalami PJK adalah 36-64 tahun. Rata-rata usia pasien di Amerika yang mengalami aterosklerotik berada pada rentang 54-72 tahun dan 75\% adalah laki laki (Espinola dkk, 2001).

Status perkawinan dalam penelitian ini menghasilkan data jumlah responden terbesar memiliki status menikah (96\%). Pernikahan dapat meningkatkan support system untuk meningkatkan kualitas hidup pasien. Penelitian yang dilakukan Panthee, dan Kritpracha (2011) menyatakan bahwa individu yang tidak memiliki pasangan menunjukkan kecemasan yang lebih besar dibandingkan yang memiliki pasangan. Kecemasanmerupakan faktorrisikoterjadinya penyakit jantung dan memengaruhi kualitas hidup secara psikologis (Rachmayanti, 2013). Adanya masalah pada pembuluh darah koroner dan masalah psikologis akibat kecemasan akan memengaruhi kualitas aktivitas hubungan seksual pada individu yang menikah (Panthee \& Kritpracha, 2011).

Penelitian ini mendapatkan data mengenai jenjang pendidikan tertinggi yaitu berada pada tingkat perguruan tinggi $(66 \%)$. Hasil penelitian tersebut berbeda dengan hasil penelitian yang dilakukan Chan, Chau, dan Chang (2005) bahwa jenjang pendidikan terbanyak dalam penelitian mereka adalah pendidikan dasar. Jenjang pendidikan tidak menjadi kontribusi dalam risiko PJK, namun akan memengaruhi pengetahuan dan perilaku dalam kesehatan. Semakin tinggi jenjang pendidikan akan memengaruhi jenis pekerjaan dan memengaruhi gaya hidup 
individu dan kemampuan untuk mengelola diri sesuai dengan pengetahuan yang didapat (Rochmayanti, 2013).

Karakterisitik pekerjaan dalam penelitian ini, sebagian besar $(26 \%)$ memiliki pekerjaan. Hasil penelitian ini sejalan dengan penelitian yang dilakukan oleh National Heart, Lung, and Blood (2012) dimana dalam penelitiannya responden terbesar memiliki pekerjaan $(45,5 \%)$. Pekerjaan sampai saat ini tidak memengaruhi risiko PJK, hal ini berarti memiliki pekerjaan atau tidak memiliki pekerjaan bukan merupakan faktor terjadinya PJK. Kondisi memiliki pekerjaan dapat menggambarkan jenis dan jumlah aktivitas yang dilakukan yang akan memengaruhi risiko PJK.

Jumlah responden yang telah melewati tindakan IKP lebih dari satu tahun dan kurang dari satu tahun memiliki proporsi yang sama $(50 \%)$. Keadaan ini menggambarkan rentang waktu proses penerimaan pasien terhadap perubahan kondisi pasca-IKP dan memengaruhi efikasi diri pasien dalam menjalani aktivitas sehari-hari yang berubah pasca-IKP terkait pengobatan, diet, dan aktivitas.

Gambaran kualitas hidup pasien pascaIKP dalam penelitian ini (25\%) mengatakan baik dalam keadaan kesehatan, dan setelah IKP $(22 \%)$ biasa-biasa saja. Penelitian di Finlandia tahun 1998 dalam Journal Nursing Researcher didapatkan hasil bahwa kualitas hidup pasien Coronary Artery Disease yang menjalani IKP memiliki kualitas hidup lebih baik setelah setahun dibandingkan dengan pasien yang melakukan pengobatan farmakologi saja (terapi fibrinolitik). Pada penelitian ini responden menyatakan terjadi perbaikan kualitas hidup di setiap dimensi kualitas hidup sebanyak 30\%. Penelitian tersebut sejalan dengan penelitian lain yang menyebutkan IKP memperbaiki kualitas hidup pada semua dimensi kualitas hidup (Blankenship, dkk., 2012).

Domain kualitas hidup yang paling bermasalah ditemukan data yang berada pada domain sosial rendah $(70 \%)$ dan domain lingkungan (70\%). Penelitian ini sangat menunjang hasil penelitian di Finlandia, bahwa faktor yang memengaruhi kualitas hidup pasien antara lain depresi, cemas, dan adanya penyakit lain yang menyertai. Faktor lain yang memengaruhi kualitas hidup adalah lingkungan dan kesehatan sosial. Penelitian yang lain menyebutkan bahwa terjadi peningkatan masalah sosial pada pasien pascaintervensi jantung, dimana mereka tidak mendapatkan pendampingan walaupun telah mendapatkan perbaikan fisik melalui IKP dan adanya masalah fungsi sosial yang tidak tercapai (Gunal, dkk., 2008). Depresi dan masalah sosial masih terjadi pada pasien pasca-IKP pada dua minggu sampai dengan satu tahun pertama. Hal ini terjadi akibat masih adanya ancaman serangan jantung berulang, cemas, dan ketakutan (Wang, dkk., 2013).

Depresi yang dialami pasien pasti akan memengaruhi fungsi sosial pasien pascaIKP. Jumlah penderita yang besar pascaIKP akibat penyakit PJK yang berada di usia lanjut diakibatkan perubahan aliran darah akibat penyempitan lumen ateri dan terjadinya penyumbatan aliran darah menuju jantung. Sumbatan tersebut berlangsung progresif dan tidak adekuatnya suplai darah sehingga menimbulkan iskemia pada sel otot yang dibutuhkan dalam aktivitas kehidupan (Smeltzer \& Bare, 2002). Pada penelitian ini, usia responden yang telah menjalani IKP berada pada rentang usia 46-66 tahun. Data tersebut menunjukan usia lanjut juga memengaruhi kualitas hidup pasien, semakin lanjut usia maka akan semakin memengaruhi kualitas hidup (Kristofferzon, Lofmark, \& Carlsson, 2005).

\section{Simpulan}

Hasil penelitian ini dapat disimpulkan bahwa kualitas hidup pasien pasca-IKP berada dalam rentang biasa-biasa saja. Intervensi keperawatan dibutuhkan untuk mengembalikan kualitas hidup secara utuh dari segi mind dan spirit. Hasil penelitian ini diharapkan dapat menjadi saran bagi perawat dalam meningkatkan peran dalam membantu pasien mencapai kualitas hidup yang optimal. Hal ini dapat dilakukan melalui peningkatan efikasi diri pasien melalui pendampingan dan pemberian informasi dalam usaha mencapai kualitas hidup yang optimal. 
Remita Ully Hutagalung: Kualitas Hidup Pasien Pascaintervensi Koroner Perkutan

\section{Daftar Pustaka}

Baas, T.A. (2004). Left main coronary artery : We are getting closer. Journal Catheterization and Cardiovascular Interventions, 46, 482483. doi: 10.1002/ccd.20014.

Blankenship, J. C., Marshall, J. Pinto, S. D., Lange, R. A., Bates, E. R., Holper, E. M., ... Chambers, C. E. (2012). Effect percutaneous coronar intervention on quality of life. Catheterization and Cardiovascular Intervention. doi: 10.1002/ccd.24376.

Chan, D.S.K., Chau, J.P.C., \& Chang, A. M. (2005). Acute coronary syndromes: Cardiac rehabilitation programmes and quality of life. Journal of Advance Nursing, 49(6) :591-599.http://www.ncbi.nlm.nih.gov/ pubmed/15737219 di unduh 11/1/2014.

Corwin, E. J. 2008. Buku saku patofisiologi. Jakarta: EGC.

Depkes .(2005). Profil kesehatan Indonesia 2004. Diakses dari http://bankdata.depkes. go.id/data\%20intranet/ProfilKes/2004/

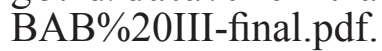

Espinola, C. K., Rupprecht, H. J., Blankenberg, S., Bickel, C., Kopp, H., Victor, A., ... Hafner, G. (2002). Impact of infectious burden on progression of carotid atherosklerosis stroke. Catheterization and Cardiovascular Interventions (35)2581-2586. doi:10.1161/01/STR..0000034789.82859. A4.

Gunal, A., Aengevaeren, H. R., Gehlmann, J. E., Luijten, J. S., Bos \& Verheugt, F. W. A. (2008). Outcome and quality of life one year after percutaneous coronary intervention octogenerarians. Netherlands Heart Journal, 16, 117-123 http://www.ncbi.nlm.nih.gov/ pmc/articles/PMC2300464.

Guyton \& Hall. (2000). Buku ajar fisiologi kedokteran. Ed.9. Jakarta: EGC.

Huynh, T., Perron, S., O'Loughlin J., Joseph, L., Labrecque, M., Tu, J. V., \& Théroux, P. (2009). Comparison of primary percutaneous coronary intervention and fibrinolytic therapy in ST Segment
Elevation Myocardial Infarction: Bayesian hierarchical meta analyses of randomized controlled trials and observasional studies. Journal of The American Heart Association, 119, 3101-3109. doi: 10.1161/ CIRCULATIONAHA.108.793745

Ibrahim, K. (2009). Kualitas hidup pasien gagal ginjal yang menjalani hemodialisa. Majalah Kedokteran Bandung 37(3).

Keeley, E. C., \& Hillis, L. D. (2007). Primary PCI for myocard infarction with ST-segment elevation. New England Journal of Medicine, 356, (1), 47-54. doi: 10.1056/NEJMct063503.

Kamm-Steigelman, L., Kimble, L. P., Dunbar, S., Sowell, R. L., \& Bairan, A. (2006). Religion, relationship and mental health in midlife women following acute myocardial infarction. Issues in Mental Health Nursing, 27(2), 144-159. http://www.ncbi.nlm.nih. gov/pubmed/16418076 di unduh 11/1/2014.

Kemenkes, R.I. (2010). Profil kesehatan Indonesia 2009. Jakarta.

Kristofferzon, M. L., Lofmark, R., \& Carlsson, M. (2005). Coping, social support and quality of life over time after myocardial infarction. Journal of Advance Nursing, 52 (2), 113-124. Diakses dari http://www.ncbi. nlm.nih.gov/pubmed/16164472.

Lucas, R. (2012). The WHO quality of Life (WHOQoL) questionnaire: Spanish development and validation studies. Quality Life Resp, 21, 161-165. doi.org/10.1017/ S1041610212001809.

Lucas, R. (2012). The WHO quality of Life (WHOQoL) questionnaire: Spanish development and validation studies. Quality Life Resp, 21, 161-165. doi.org/10.1017/ S1041610212001809.

Moonen, L. A., Van't Veer, M., \& Pijls, N. H. J. (2010). Procedural and long term outcome of primary PCI in octogenarians .Netherlands Heart Journal, 18 (3), 129-135. Diakses dari http://www.ncbi.nlm.nih.gov/pmc/articles/ PMC2848355/. 
Remita Ully Hutagalung: Kualitas Hidup Pasien Pascaintervensi Koroner Perkutan

National Heart, Lung, and Blood. (2012). Coronary heart disease. Diakses dari http:// www.nhlbi.nih.gov/health/public/heart/ other/chd_atglance.pdf[16/09/13].

NHLBI. (2012). Who is at risk coronary heart disease. Diakses dari http://www.nhlbi.nih. gov/health/health-topics/topics/cad/atrisk. html.

Panthee, B., \& Kritpracha, C. (2011). Review anxiety and quality of life patient with myocard infarction. Nurse Media Journal of Nursing, 1(1), 105-115. Diakses dari http:// ejournal.undip.ac.id/index.php/medianers/ article/view/750.

Price, S., \& Wilson, L. (2010). Patofisiologi konsep klinik proses-proses Penyakit. Jakarta: EGC.

Rachmayanti, R. D. (2013). Penggunaan media panggung boneka dalam pendidikan personal hygiene cuci tangan menggunakan sabun di air mengalir. Jurnal Promosi dan Pendidikan Kesehatan Indonesia, 1(1), 1-8.

Sasayama, S. (2008). Heart desease in Asia. Circulation, 118 (25), 2669-2671. doi: 10.1161/CIRCULATIONAHA.108.837054.

Skevington, S. M., Lotfy, M., \& O'Connell, K. A. (2004). The World Health Organization's WHOQOL-BREF quality of life assessment: psychometric properties and results of the international field trial: A report from the WHOQOL group. Quality of life Research, 13(2), 299-310.
Smeltzer, S. C., \& Bare, B. G. (2002). Buku ajar keperawatan medikal bedah Brunner \& Suddart. Jakarta: EGC.

Turkish Society of Cardiology. (2007). Nursing care guidelines in percutaneous coronary and valvular interventions. Diakses dari http://www.tkd-online.org/ kilavuzlar/ulusal/TKD_NursingGuidelines Percutaneous.pdf.

Wang, Z. J., Guo, M., Si, T. M., Jiang, M. M., Liu, S. M., Liu, Y. Y., ... Zhou, Y. J. (2013). Association of depression with adverse cardiovascular events after percutaneous coronary intervention. Coronary artery disease, 24(7), 589-595.

Weintraub, W. S., Spertus, J.A., Kolm, P., Maron, D. J., Zhang, Z., Jurkovitz, C., ... Boden, W. E. (2008). Effect of PCI on quality of life patients with stable coronary desease. New England Journal of Medicine,359 (7), 677-687.

WHO. (2013). WHO Media Center. Diakses dari http://www.who.int/mediacentre/factshe ets/.

World Heart Federation. (2014). Cardivacular disease risk factor. Diakses dari http://www. world-heart-federation.org/press/fact-sheets/ cardiovascular-disease-risk-factors.

Zhao. (2008). Depression and anxiety before and after percutaneous coronar intervention and their relationship to age. Journal of Geriatric Cardiology 13, 203-207. 